\title{
TGF- $\beta$ Signaling in Breast Cancer Cell Invasion and Bone Metastasis
}

\author{
Yvette Drabsch • Peter ten Dijke
}

Received: 9 March 2011 / Accepted: 14 March 2011 /Published online: 15 April 2011

(C) The Author(s) 2011. This article is published with open access at Springerlink.com

\begin{abstract}
The contribution of transforming growth factor $\beta$ (TGF- $\beta$ ) signaling to breast cancer has been studied for more than two decades. In an early phase TGF- $\beta$ may act as a tumour suppressor, while later, when cells have become resistant to its anti-mitogenic effects, the role of TGF- $\beta$ switches towards malignant conversion and progression. TGF- $\beta$ stimulates cell invasion and modifies the microenvironment to the advantage of cancer cells. Studies have shown that TGF- $\beta$ promotes bone and lung metastasis via different mechanisms. The therapeutic strategies to target the TGF- $\beta$ pathway in breast cancer are becoming increasingly clear. This review will focus on the role TGF- $\beta$ in breast cancer invasion and metastasis.
\end{abstract}

Keywords EMT - Invasion · Metastasis .

Microenvironment $\cdot$ Stroma $\cdot$ TGF- $\beta$

\begin{tabular}{ll}
\multicolumn{2}{l}{ Abbreviations } \\
ANGPTL4 & Angiopoietin-like 4 \\
AnxA1 & Annexin A1 \\
BLBC & Basal-like breast cancers
\end{tabular}

Acknowledgment of Financial or Material Support Our studies on TGF- $\beta$ in cancer are supported by Centre for Biomedical Genetics, Netherlands Organization for Scientific Research and Swedisch Cancer Society.

Y. Drabsch $\cdot$ P. ten Dijke $(\bowtie)$

Department of Molecular Cell Biology and Centre for Biomedical Genetics, Leiden University Medical Center,

Postbus 9600, 2300 RC Leiden, The Netherlands

e-mail: p.ten_dijke@lumc.nl

Y. Drabsch

e-mail: y.s.drabsch@lumc.nl

P. ten Dijke

Ludwig Institute for Cancer Research and Uppsala University,

Box 595, 75124 Uppsala, Sweden

$\begin{array}{ll}\text { BMP } & \text { Bone morphogenetic protein } \\ \text { CAF } & \text { Carcinoma-associated fibroblasts } \\ \text { CAR } & \text { Coxsackie- and adenovirus receptor } \\ \text { CDK } & \text { Cyclin-dependent kinase } \\ \text { Cre } & \text { Cre recombinase } \\ \text { CTGF } & \text { Connective tissue growth factor } \\ \text { CXCR4 } & \text { C-X-C chemokine receptor type } 4 \\ \text { ECM } & \text { Extracellular matrix } \\ \text { EGF } & \text { Epidermal growth factor } \\ \text { EMT } & \text { Epithelial-mesenchymal transition } \\ \text { FARP } & \text { FERM RhoGEF (ARHGEF) and pleckstrin } \\ & \text { domain protein } \\ \text { FGF } & \text { Fibroblast growth factor } \\ \text { GR-1 } & \text { Granulocyte differentiation antigen 1 } \\ \text { HDM2 } & \text { Human double minute 2 } \\ \text { HMEC } & \text { Human mammary epithelial cells } \\ \text { HIF-1 } \alpha & \text { Hypoxia-inducible factor-1 } \alpha \\ \text { IL-11 } & \text { Interleukin 11 } \\ \text { MAP } & \text { Mitogen activated protein } \\ \text { MDM2 } & \text { Murine double minute } 2 \\ \text { MET } & \text { Mesenchymal-epithelial transition } \\ \text { MMP } & \text { Matrix metalloproteinase } \\ \text { MMTV } & \text { Mouse mammary tumour virus } \\ \text { M-RIP } & \text { Myosin phosphatase Rho interacting protein } \\ \text { Nedd9 } & \text { Neural precursor cell expressed developmen- } \\ & \text { tally down-regulated 9 } \\ \text { PTHrP } & \text { Parathyroid hormone-related protein } \\ \text { RANKL } & \text { Receptor activator of nuclear factor Kappa-B } \\ & \text { ligand } \\ \text { SDF-1 } & \text { Stromal-derived factor-1 } \\ \text { shRNA } & \text { Short hairpin RNA } \\ \text { siRNA } & \text { Small interfering RNA } \\ \text { TGF- } \beta & \text { Transforming growth factor- } \beta \\ \text { T } \beta \text { RI } & \text { TGF- } \beta \text { type I receptor } \\ \text { T } \beta \text { RII } & \text { TGF- } \beta \text { type II receptor } \\ \text { uPAR } & \text { Urokinase receptor } \\ & \end{array}$




$\begin{array}{ll}\text { VEGF } & \text { Vascular endothelial growth factor } \\ \text { WAP } & \text { Whey acidic protein }\end{array}$

\section{Introduction}

Breast cancer is the most common cancer in women and a major cause of morbidity or mortality. Worldwide, approximately 350,000 women die from breast cancer each year [1]. Many factors are currently studied to understand the causes of breast cancer. These include lifestyle [reviewed in 2], environmental [for example 3], genetic and biological factors. One of the genetic and biological factors in breast cancer biology that is widely studied is the secreted cell to cell signaling molecule, transforming growth factor- $\beta$ (TGF- $\beta$ ).

TGF- $\beta$ is part of a large family of polypeptide growth factors that includes activins, inhibins, and bone morphogenetic proteins (BMPs). Three human TGF- $\beta$ isoforms, which are structurally and functionally closely related, have been described. All three isoforms are secreted as latent precursor molecules. Proteolytic cleavage, interaction with integrins, or $\mathrm{pH}$ changes in the local environment activate latent TGF- $\beta$ [4]. Classic TGF- $\beta$ signaling involves the binding of TGF- $\beta$ to TGF- $\beta$ type II receptors (T $\beta$ RIIs), recruitment of type I receptors (T $\beta$ RIs), transphosphorylation by T $\beta$ RII kinase, and the subsequent phosphorylation of receptor regulated (R-)Smad2 and Smad3. Bone morphogenetic proteins (BMPs) signal specific BMP type I and type II receptors, and stimulate the activation of R-Smad1, 5 and 8. Phosphorylated Smads form heteromeric complexes with common mediator (co-)Smad4 that then accumulate into the nucleus. The Smad complexes interact with transcription factors, co-activators, and co-repressors where they participate in the regulation of target gene expression [reviewed in 5]. Besides the canonical TGF- $\beta /$ Smad pathway, TGF- $\beta$ can directly activate non-Smad signaling pathways $[6,7]$, including the mitogen activated protein (MAP) kinases. Erk was found to be phosphorylated via a direct T $\beta$ RI-induced phosphorylation of She [8]. In addition, small GTPases such as Ras, Rho, Rac and CDC42, have been implicated in non-Smad TGF- $\beta$ signaling [9-11].

TGF- $\beta$ is a very potent growth inhibitor of primary human mammary epithelial cells. Loss of TGF- $\beta$ growth inhibition and increased expression of TGF- $\beta$ have been associated with malignant conversion and progression in breast cancer. Specific mutation of TGF- $\beta$ signaling components occurs only occasionally in breast cancers. Rather, TGF- $\beta$ growth response is abrogated by changes in the profile of other active signaling networks or the relative availability of transcriptional co-repressors or co-activators that bind to and modulate the canonical Smad pathway [12]. Estrogens also appear to negatively regulate TGF- $\beta$ signaling in breast cancer [13] and there is evidence that many pathway components may be epigenetically regulated during critical transitions in malignant progression [14]. Moreover, a large number of reports indicate that TGF- $\beta$ can turn into a promoter of progression at later tumour stages [15]. In support of this notion is clinical evidence that indicates a correlation between expression of the TGF$\beta$ ligands and poor patient outcome [16-19].

TGF- $\beta$ supports tumour progression by stimulating the transdifferentiation of epithelial cancer cells into migratory mesenchymal cells $[20,21]$, by promoting cell invasion, and dissemination to distant sites [22], enhance angiogenesis [23] and mediating immune evasion of tumour cells [24]. Thus, besides direct effects on tumour cells, TGF- $\beta$ influences the tumour microenvironment to stimulate local movement and survival of neoplastic cells. The metastasis of breast cancer cells to remote tissues is not a random process. For example, decreased BMP7 in primary breast cancer is significantly associated with the formation of bone metastasis. It is theorised that BMP7 supports MET and inhibits TGF- $\beta$-induced metastasis to the bone [25]. The mechanisms that underlie the choice of residence at distant organs, such as bone and lung, are emerging [26].

The mechanisms of TGF- $\beta$-induced growth arrest via the induction of cyclin-dependent kinase (CDK) inhibitors and repression of c-Myc protooncogene, and how cells become refractory to its cytostatic effects by mutations or epigenetic mechanisms are well understood [reviewed in 22] and will not be discussed here. The signaling cascades involved in its pro-oncogenic roles are emerging from recent studies and are the focus of this review. Here we will discuss recent advances into the molecular mechanisms that control EMT and tumour invasion of breast cancer, the interaction of tumour cells with neighbouring stromal cells and metastasis of breast cancer cells to bone and lung and specifically focus on the role of TGF- $\beta$ in these processes.

\section{Epithelial Plasticity}

EMT is a highly coordinated process that involves a complex series of events [27]. EMT starts with apicobasal polarity loss and the dissolution of tight junctions, which permit the intermingling of apical and basolateral membrane components [28]. In addition, other cell-cell junctions disassemble and degrade the underlying basement membrane. The cell surface protein that mediates epithelial connection to neighbouring cells and the basement membrane, E-cadherin, is replaced by N-cadherin. The transient adhesive properties of $\mathrm{N}$-cadherin prime the cell for the mesenchymal phenotype. Cytoskeletal elements are then 
reorganized and stress fibers replace the peripheral actin cytoskeleton, and vimentin replaces cytokeratin intermediate filaments. These changes cause the cell to change from a cuboidal to a spindle shape. It is then that the cell acquires the ability to move and invade into the extracellular matrix (ECM) $[29,30]$.

TGF- $\beta$ treatment has been shown to cause delocalization and downregulation of cell-cell contact proteins (such as ZO-1, E-cadherin, $\beta$-catenin), cytoskeleton reorganization (stress fiber assembly, myosin light chain phosphorylation), and robust $\alpha$-smooth muscle actin synthesis [31]. Frequently, Namru Murine Mammary Gland (NMuMG) breast cancer cells have been used for studies involving TGF- $\beta$ induced EMT $[32,33]$. More recently, TGF- $\beta$ has been shown to be involved with the early stage changes of EMT in Human Mammary Epithelial Cells (HMEC). The epithelial cell polarity marker ZO-1 was repressed with the addition of TGF- $\beta$. Furthermore, a rapid increase in expression of mesenchymal markers Vimentin and Fibronectin is seen after TGF- $\beta$ treatment of HMECs [34].

While initially the occurrence of EMT in cancer was received with skepticism, the concept of epithelial cancer cell plasticity contributing to cancer progression is now gaining acceptance [27]. Evidence for the role of EMT in cancer is complicated by the fact that at the distant site the metastatic cells most likely need to undergo a reversion or mesenchyal to epithelial transition (MET), permitting colonization of the distant site [29]. EMT is a transient and reversible process in the course of cancer progression. This was recently shown by Jo et al., who could reverse EMT by targeting the urokinase receptor (UPAR) [35]. The first direct evidence of EMT in the local invasion of tumour cells was obtained by cell fate mapping of epithelial tumour cells in Whey Acidic Protein (WAP)Myc transgenic mice [36].

EMT rarely occurs homogenously across the whole tumour. The exceptions include diffuse lobular carcinoma [37] and sarcomatoid tumour of the breast, also referred to as spindle-cell carcinoma tumours [31]. Based on the expression of EMT markers, EMT appears to occur at the invasive front of the tumour $[38,39]$. These tumour cells are primed to undergo EMT by genetic and epigenetic changes. Extracellular inputs, such as the activation of TGF- $\beta$ and Wnt signaling [40] at the leading edge of the tumour are coupled with the expression of EMT regulators such as Snail/Slug/Twist, Cripto-1 and Six1 [34, 41-46], causes cells to acquire a mesenchymal phenotype that allow them to invade locally and escape from the primary tumour (Fig. 1). This was discussed in detail in the review by Micalizzi et al. [38] on EMT in breast cancer.

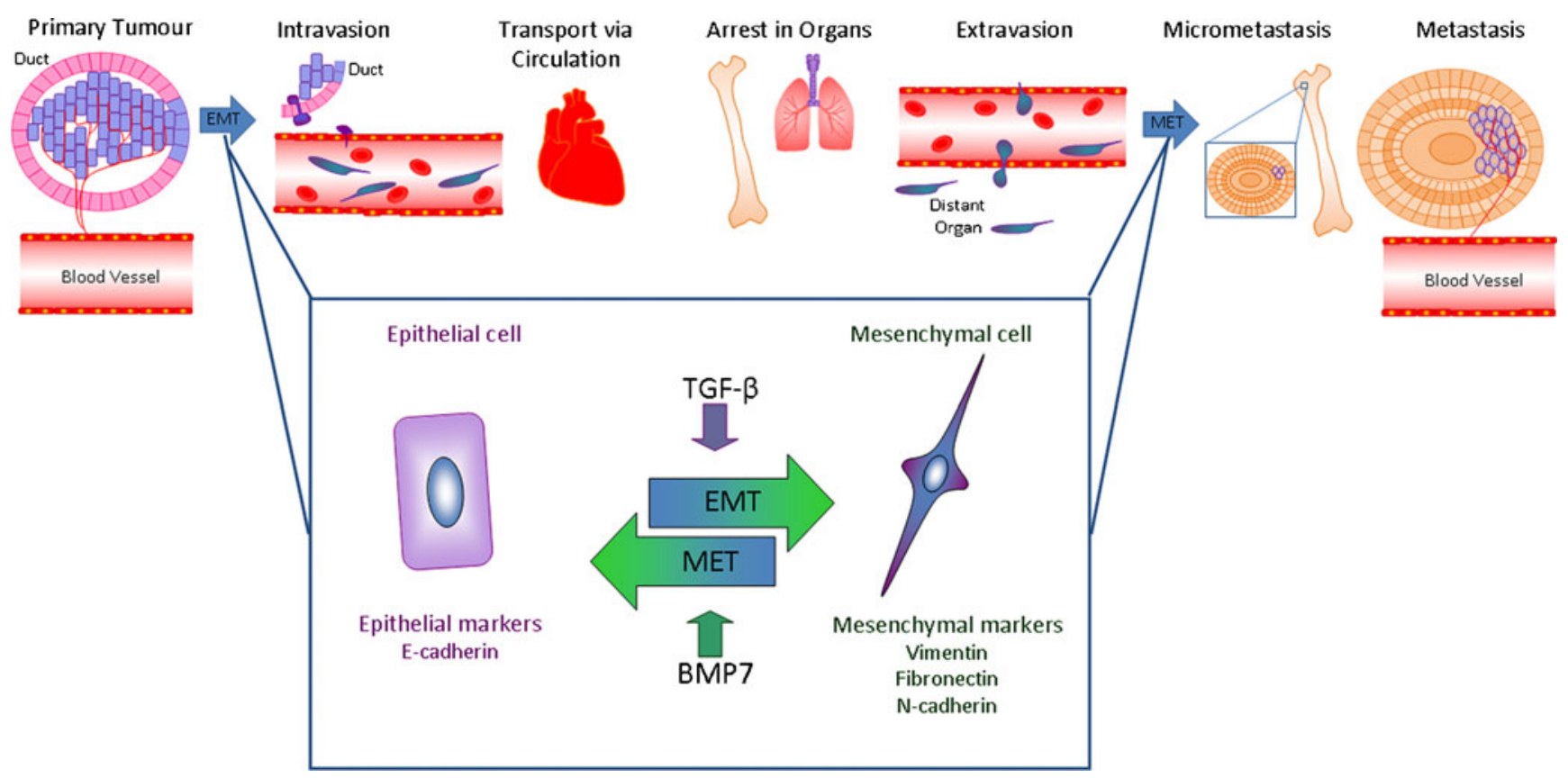

Fig. 1 The metastasis cascade. Epithelial cells at the edge of the primary tumour, within a duct in the mammary gland, when triggered by interactions with the underlying stroma, will breach the basal membrane, undergo EMT as they invade into the stroma and become mesenchymal. The newly acquired mesenchymal state allows local invasion and intravasation within nearby vessels, resulting in circulation of the tumour cells. The circulating tumour cells will extravasate into the tissue of distant organs. The microenvironment of the distant organ has a normal stroma and lacks the signals that induced EMT. The new microenvironment triggers the tumour cells to undergo MET and establish within the tissue. Although most of the tumour cells that shed from the primary tumour site will die either during transport or at the site of landing, some will create micrometastases. While most of these micrometastases may remain dormant, some will proliferate forming a full blown metastasis 
TGF- $\beta$ was identified as one of the main inducers of EMT. TGF- $\beta$-induced EMT of NMuMG breast cancer cells was found to be mediated via Smad3 and Smad4 [47]. Activated Smads mediate EMT by inducing the expression of transcriptional repressors, such as Snail, Slug and HMGA2. The Smads also make complexes with these repressors to enhance their transcriptional effects [41, 48]; a SNAIL1-SMAD3/4 complex was shown to repress Coxsackie- and adenovirus receptor (CAR), occludin and E-cadherin transcription. A strong correlation was found between loss of CAR and E-cadherin and nuclear coexpression of SNAIL1 and SMAD3/4 at the invasive front of breast carcinomas [40].

Smad proteins downregulate the expression of the miRNA-200 family to induce EMT [49]. Also non-Smad mediated signaling has been implicated in TGF- $\beta$-induced EMT. P38 and Rho kinase inhibitors attenuate TGF- $\beta$ induced stress fiber formation and the subsequent relocalization of E-cadherin [9]. TGF- $\beta$-induced phosphatidylinositol 3-kinase and Akt activation was required for TGF- $\beta$ induced ZO-1 relocalization from tight junctions and change in cell morphology [50]. Furthermore, TGF- $\beta$ receptor-induced phosphorylation of Par6 leads to a loss in tight junctions and contributes to EMT in the transplantable mouse mammary tumour cell line, EMT6 [42].

A recent paper investigated the hypothesis whether an actin regulatory protein, Annexin A1 (AnxA1), is functionally involved in breast cancer progression [51]. AnxA1 was found to be highly expressed in basal-like cancers (BLBC) compared to luminal-like breast cancer cells. BLBC-like cells converted from a mesenchymal to an epithelial morphology upon AnxA1 knockdown, and that ectopic expression of AnxA1 in the luminal-like MCF-7 human breast cancer cell line increased cell scattering and Smad3/4 transcriptional reporter activity. These latter effects were mediated by TGF- $\beta$-like activity as they could be blocked by the TGF- $\beta$ type I receptor kinase inhibitor SB-431542 [51]. Moreover, AnxA1 knockdown in the highly invasive 4T1 mouse breast cancer cells reduced the number of surface metastases in the lungs, but had no effect on primary tumour growth [51].

Araki et al. studied the Smad-dependent TGF- $\beta$ signaling in the context of breast cancer progression [52]. In this study, the authors reported that TGF- $\beta$ increased the expression of the E3 ubiquitin ligase human double minute 2 (HDM2) in a Smad3/4-dependent manner. Similar changes were seen in murine double minute 2 (MDM2) expression during murine EMT. The identification of HDM2 as a downstream target of TGF- $\beta$ represents a critical pro-survival mechanism in cancer progression and provides a potential therapeutic intervention target in latestage cancer. A recent paper investigated the properties of EMT induced by TGF- $\beta$ in cooperation with fibroblast growth factors (FGFs) [43]. Moreover, the cells generated through EMT mediated by FGF- 2 and TGF- $\beta$ facilitated cancer cell invasion, when the cells undergoing EMT were mixed with cancer cells. Therefore, the results of this paper show that TGF- $\beta$ and FGF- 2 cooperate with each other and may regulate EMT in the cancer microenvironment.

It has also been shown that TGF- $\beta$ stimulation of EMT elicits a fundamental change in the coupling of EGFR to its downstream effectors. Furthermore, Wendt et al. show that in 3D-organotypic culture post-EMT mammary epithelial cells manifest as dense cellular aggregates that are characteristic of highly metastatic breast cancer cells [44]. Also, Sabbah et al. have demonstrated that CCN5, an estrogen-inducible gene in estrogen receptor-positive cell lines, acts as a transcriptional repressor. CCN5 was shown to regulate tumour progression by repressing expression of genes associated with EMT as well as expression of key components of the TGF- $\beta$ signaling pathway, prominent among them T $\beta$ RII receptor [53].

\section{Invasion}

Invasion into neighbouring tissue and ectopic survival are required for cancer progression and are a requirement to form metastasis [54]. It is known that the movement of neoplastic cells is not a random process. However, the mechanisms controlling the neoplastic cells movement, survival in foreign tissue environments, and choice of residence at a final destination are not clear [38]. Invasion and metastasis are the cause of malignancy and responsible for treatment failure [55].

Molecular profiles of isolated luminal epithelial and myoepithelial cells have identified a complex network involving TGF- $\beta$, Hedgehog, cell adhesion, and p63 to be required for myoepithelial cell differentiation, the elimination of which resulted in loss of myoepithelial cells and progression to invasion [56]. Recent investigations using invasive mouse breast tumour cells have shown that Fra-1, a member of the FOS family of transcription factors, is involved in breast tumour invasion. This Fra-1 initiates activation of the IL-6/JAK/Stat3 signaling pathway, which creates a malignant switch in breast tumour cells. The subsequent increased release of proangiogenic factors MMP-9, VEGF, and TGF- $\beta$ from tumour cells causes an intensified invasion and progression of breast cancer [57].

Tumour cells often form related structures called invadopodia that are thought to promote invasion and metastasis. Organization of the invadopodia requires signaling through phosphatidylinositide 3-kinase and $\mathrm{Src}$ kinase. Furthermore, degradation of the ECM requires extracellular signal-regulated kinase signaling, and each of 
these pathways is activated by TGF- $\beta$ in CA1D human breast cancer cells [58].

An elegant TGF- $\beta$-dependent invasion assay system, consisting of spheroids of MCF10A1 normal breast epithelial cells and RAS-transformed (pre-)malignant derivatives embedded in collagen gels, has recently shown that the TGF- $\beta /$ Smad pathway induces breast cancer cell invasion through the up-regulation of matrix metalloproteinase (MMP) 2 and 9 [59]. Both basal and TGF- $\beta$-induced invasion of these cell lines was found to correlate with their tumourigenic potential. Furthermore, basal invasion was strongly inhibited by the TGF- $\beta$ receptor kinase inhibitor SB-431542, indicating the involvement of autocrine TGF- $\beta$ or TGF- $\beta$-like activity. TGF- $\beta$-induced invasion in premalignant and highly malignant breast cells was also inhibited upon specific knockdown of Smad3 or Smad4.

Intravital imaging has been used to demonstrate a reversible transition to a motile state as breast cancer cells spread. Giampieri et al. were able to demonstrate that transient TGF- $\beta$ signaling is essential for blood-borne metastasis. TGF- $\beta$ was shown to be capable of switching cells from cohesive to single cell motility through a transcriptional program involving Smad4, EGFR, neural precursor cell expressed, developmentally down-regulated 9 (Nedd9), myosin phosphatase Rho interacting protein (MRIP), FERM, RhoGEF (ARHGEF) and pleckstrin domain protein (FARP) and Rho C. Furthermore, they showed that a blockade of TGF- $\beta$ signaling prevented cells moving singly in vivo, but did not inhibit cells moving collectively.
In fact, the cells restricted to collective invasion were capable of lymphatic invasion, but not blood-borne metastasis [60]. Thus, although TGF- $\beta$ is known to suppress epithelial cell proliferation and therefore primary tumourigenesis, it has been shown to promote breast cancer progression via the induction of EMT and tumour cell invasion.

\section{Tumour Stroma Interactions and the Microenvironment}

Tumour progression may be a product of an evolving crosstalk between different cell types within the tumour and its surrounding supporting tissue, or tumour stroma (Fig. 2). The tumour compartment is defined by genetically abnormal cells. It is the surrounding and interwoven stroma that can provide a connective-tissue framework of the tumour tissue. This framework includes the ECM as well as cellular components such as fibroblasts, immune and inflammatory cells, and blood vessel cells [61, 62]. Its constitution resembles that of the granulation tissue formed during wound healing [63]. In fact, stromal alterations during wound healing, induced by TGF- $\beta$, can be an important determinant of tumour growth [64]. Similarly to the development and function of normal organs, it is the interaction between cancer cells and their microenvironment that can largely determine the phenotype of the tumour [65]. For example, recent studies have shown that the establishment of human breast tumour xenografts in
Fig. 2 The microenvironment. A vicious cycle, where tumour cells alter the bone microenvironment by stimulating osteoclast factors, such as PTHrP, IL-11 and CTGF. These factors act on osteoblasts to stimulate the release of RANKL, which promote osteoclast formation and function (I). CAFs secrete stroma-derived factors, such as SDF-1, which directly interacts with its receptor on breast cancer cells, CXCR4, and directs tumour cell migration (II). TGF- $\beta$ contributes to the regulation of angiogenesis through direct and indirect mechanisms (III). In the microenvironment TGF- $\beta$ has immunosuppressive effects on immune cells involved in the antitumour response following its secretion by stromal cells and various tumour cells (IV)

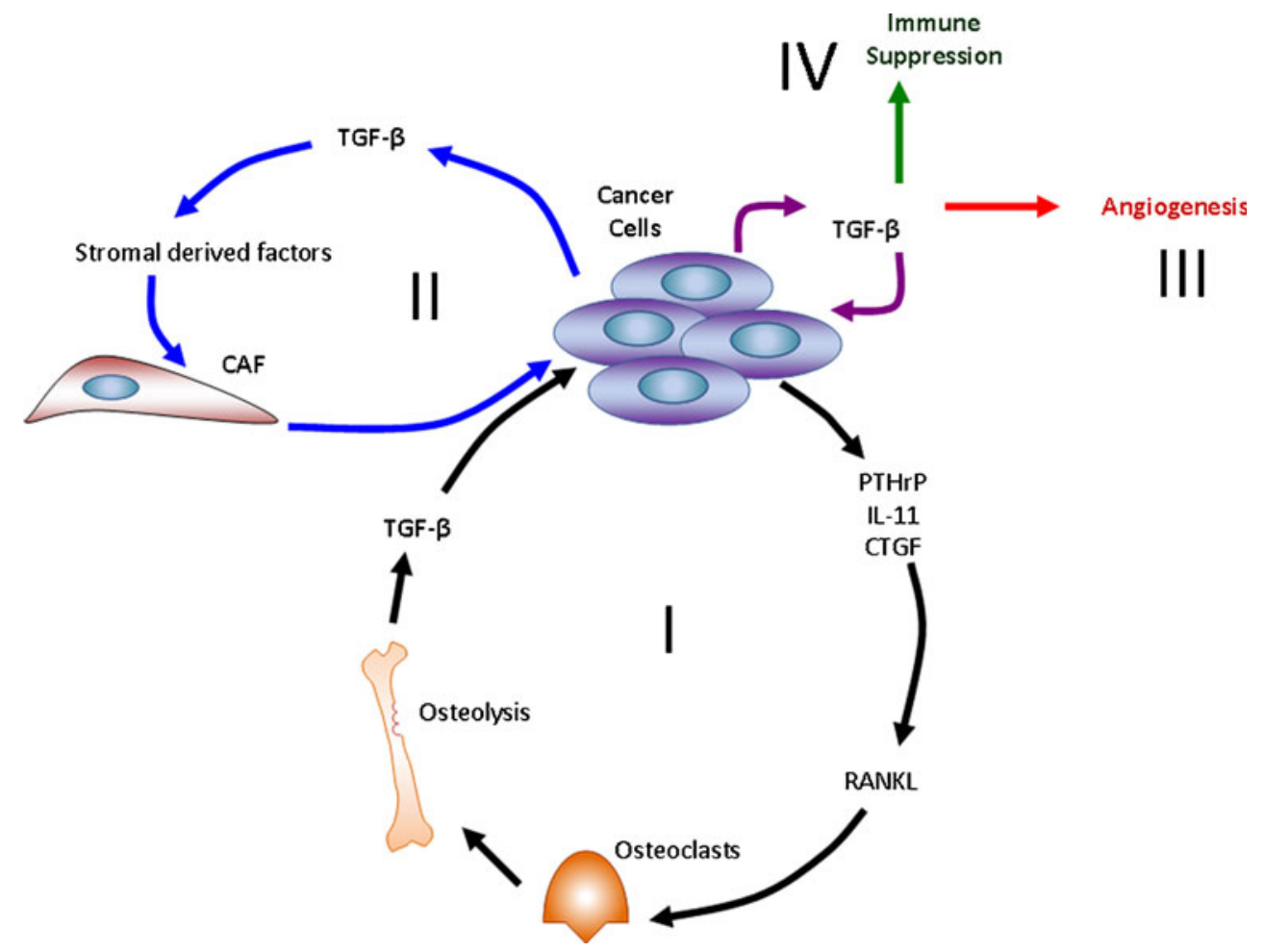


mice depends on the presence of human tumour-derived stromal fibroblasts [66-68].

Frequently present in the stroma of human breast carcinomas are carcinoma-associated fibroblasts (CAFs). The precise cellular origins of CAFs and the molecular mechanisms by which these cells evolve into tumourpromoting myofibroblasts remain unclear [69]. Using a coimplantation breast tumour xenograft model, Kojima et al. show that resident human mammary fibroblasts progressively convert into cancer-associated myofibroblasts during the course of tumour progression [70].

TGF- $\beta$-mediated carcinoma suppression is not limited to cell-autonomous signaling. Recent results that highlight the role of stromal-epithelial crosstalk in the regulation of cancer have shown that TGF- $\beta$ signal transduction in stromal fibroblast can be important for the suppression of tumourigenesis in the adjacent epithelium [71-73]. Conditional inactivation of the T $\beta$ RII gene in mouse fibroblasts resulted in intraepithelial neoplasia in the prostate and invasive squamous cell carcinoma of the forestomach, and both were associated with an increased abundance of stromal cells [71]. These T $\beta$ RII-deficient fibroblasts promoted growth and invasion of co-transplanted mammary carcinoma cells $[72,73]$.

In addition, CAFs can increase the tumourigenic ability of cancer cells. Tumourigenicity of normal mammary epithelial cells was indeed shown to be significantly enhanced by the irradiated fibroblasts in vivo [74]. The enhancement was due to the overexpression of TGF- $\beta$ from the irradiated stroma [75]. In another study, CAFs were isolated from patients with invasive breast cancer. It was shown that TGF- $\beta$ significantly increased the myofibroblast percent and invasion rate in CAF cultures. In fact, the CAFs were measurably different from normal fibroblasts in response to TGF- $\beta$, suggesting that TGF- $\beta$ stimulates changes in CAFs that foster tumour invasion [76].

It has also been demonstrated that the tumour microenvironment facilitates metastatic spread by eliciting reversible changes in the phenotype of cancer cells. Bonemarrow-derived human mesenchymal stem cells, when mixed with otherwise weakly metastatic human breast carcinoma cells, cause the cancer cells to increase their metastatic potency greatly when this cell mixture is introduced into a subcutaneous site and allowed to form a tumour xenograft [68]. The breast cancer cells stimulate de novo secretion of the chemokine CCL5 (also called RANTES) from mesenchymal stem cells, which then acts in a paracrine fashion on the cancer cells to enhance their motility, invasion and metastasis.

It is well known that tumour associated macrophages, monocytes and neutrophils can promote tumour progression [77, 78]. However, evidence now supports a significant role for immature myeloid cells as promoters of tumour progression and metastasis [79]. In mouse models, these cell populations are often identified by their cell surface expression of granulocyte differentiation antigen 1 (GR-1) and CD11b proteins. Within the GR-1+ $\mathrm{CD} 11 \mathrm{~b}+$ cell population it has been shown that the GR$1^{\text {high }}$ populations enriches for the polymorphonuclear cells whereas the GR $1^{\text {int/low }}$ population enriches for the mononuclear cells. Importantly, the authors suggest that the mononuclear fraction is better able to suppress CD8+ Tcell mediated immunity than the polymorphonuclear fraction [80]. Another study has demonstrate that Gr-1+ $\mathrm{CD} 11 \mathrm{~b}+$ myeloid cells are recruited into mammary carcinomas with T $\beta$ RII deletion and directly promote tumour metastasis [81].

It is becoming clear that the crosstalk between the cancer cells and the microenvironment plays a key role in the progression of cancer, and understanding this mutual relationship would eventually enable better treatment of patients, potentially by targeting CAFs.

\section{Metastasis}

Metastasis is a complex, multi-step process by which primary tumour cells invade adjacent tissue. These cells enter the systemic circulation (intravasate), translocate through the vasculature, and arrest in distant capillaries where they extravasate into the surrounding tissue parenchyma, and these microscopic growths (micrometastases) proliferate into macroscopic secondary tumours [82]. Metastasis is the result of several sequential steps and represents a highly organized, non-random and organselective process [83] that involves interactions from a variety of proteolytic enzymes, growth factors, and cell-cell and cell-substrate adhesion molecules [84].

In numerous models of breast cancer associated invasion and metastasis, activated TGF- $\beta$ signaling induces increased aggressiveness. For example, in mice overexpressing the Neu oncogene, activated TGF- $\beta$ signaling increases the number of lung metastases even while decreasing the growth of the primary tumour [35]. Likewise, ablation of TGF- $\beta$ signaling in the same model decreases lung metastasis while also decreasing the latency of primary tumour growth, again emphasizing the dual functions of TGF- $\beta$ signaling in tumourigenesis [37]. Additionally, clinical evidence suggests a correlation between expression of the TGF- $\beta$ ligands and poor patient outcome [16-18, 39]. Furthermore, activated TGF- $\beta$ signaling has been observed in breast cancer bone metastases and contributes to the establishment of these lesions [19, 84, 85]. There have also been many specific studies to analyse the role of TGF- $\beta$ in tumour metastasis to lung [29]. 


\section{Breast to Bone Metastasis}

Bone metastases are common in patients with advanced breast cancer. Tumour cells co-opt bone cells to drive a feed-forward cycle which disrupts normal bone remodeling to result in abnormal bone destruction or formation and tumour growth in bone [86, 87]. There is abundant evidence to support the role of TGF- $\beta$ as a major bonederived factor. TGF- $\beta$ promotes a feed-forward cycle responsible for tumour growth and (Fig. 2) in bone. Osteolytic bone destruction is caused when tumours in bone secrete osteolytic factors, such as parathyroid hormone-related protein (PTHrP) and interleukin 11 (IL11) [88]. TGF- $\beta$ is released and activated from the mineralized bone matrix by osteoclastic resorption and further induces tumour production of osteolytic and prometastatic factors including PTHrP and IL-11 [89]. Human breast cancer bone metastases have increased PTHrP expression, more so than primary breast cancers [90]. PTHrP is a central mediator of TGF- $\beta$ induced osteolytic metastases; PTHrP neutralizing antibodies blocked the development and progression of breast cancer bone metastases in mouse models [91]. Another paramount study in 1999 showed that a dominant negative TßRII stably expressed in the breast cancer cell line MDA-MB231 rendered the cells unresponsive to TGF- $\beta$, inhibited PTHrP secretion induced by TGF- $\beta$ and suppressed bone metastases in a mouse model [92]. TGF- $\beta$ increases PTHrP secretion from MDA-MB-231 cells via Smad and p38 MAP kinase pathways [93]. Furthermore, TGF- $\beta$ released during bone resorption is likely to have direct effects on bone cells, stimulating osteoclastic bone resorption and inhibiting osteoblast differentiation.

The complexity in the origin of bone metastases has been exemplified by recent transcriptional profiling of subpopulations of human breast cancer cells with an aggressive bone metastases phenotype [94, 95]. Many of these genes, such as IL-11, connective tissue growth factor (CTGF), C-X-C chemokine receptor type 4 (CXCR4), and MMP1 have effects on bone cells [96], which could promote bone metastases. Bone resorption is stimulated by IL-11 and MMP-1 causing an increase in osteoblast production of receptor activator of nuclear factor kappa-B ligand (RANKL) [97]. CXCR4, a chemokine receptor that binds to the osteoblast product stromal-derived factor-1 (SDF-1) produced by osteoblasts to promote homing of cancer cells to bone [98-100]. CTGF stimulates osteoblast proliferation as well as angiogenesis [101]. These genes act cooperatively when expressed together, to cause osteolytic metastasis by promoting homing to bone, angiogenesis, and invasion [102]. Among the bone metastasis genes identified, Kang et al. showed that IL-11 and CTGF were regulated by TGF- $\beta$ via the classical TGF- $\beta /$ Smad pathway in metastatic cells [84]. Other studies indicate that CXCR4 and MMP- 1 are also regulated by TGF- $\beta[98,99]$.

Since these first studies into TGF- $\beta$ and the bone microenvironment, there have been many advances. Recent evidence has suggested that Gli2, a Hedgehog signaling molecule, is required for TGF- $\beta$ to stimulate PTHrP expression and that blocking Hedgehog-independent Gli2 activity will inhibit tumour-induced bone destruction [103]. Using a murine syngeneic model that mimics osteolytic changes associated with human breast cancer, one laboratory has examined the role of tumour-bone interaction in tumour-induced osteolysis and malignant growth in the bone microenvironment [104]. T $\beta$ RII was identified as a commonly upregulated gene at the tumour-bone interface. Moreover, nuclear localization of phospho-Smad2 was higher in tumour cells and osteoclasts at the tumour-bone interface as compared to the tumour-alone area [104]. A mouse model sing Cre/LoxP technology, with the WAP promoter driving transgenic expression of Cre recombinase (Cre), ablated the T $\beta$ RII expression specifically within mouse mammary alveolar progenitors [105]. Transgenic expression of the polyoma virus middle $\mathrm{T}$ antigen, under control of the mouse mammary tumour virus (MMTV) enhancer/promoter, was used to produce mammary tumours in the absence or presence of Cre or T $\beta$ RII. The loss of TGF- $\beta$ signaling was significantly correlated with increased tumour size and enhanced carcinoma cell survival.

Human breast cancer bone metastases show active Smad signaling in bone metastasis by accumulation of phosphorylated Smad2 in the nucleus of tumour cells [84].

Knockdown of Smad4 expression in breast cancer cells reduced growth of bone metastases in a mouse model [47, 84]. Different studies in mouse models of bone metastases, using live imaging of tumour cells by bioluminescence, have shown that TGF- $\beta$ signaling is activated in the bone metastases, but not in metastases to adrenal glands $[12,84$, $106]$. In this preclinical model, either anti-TGF- $\beta$ therapy with a small molecule inhibitor of T $\beta$ RI kinase activity or a bisphosphonate inhibitor of bone resorption was effective to decrease TGF- $\beta$ signaling activity in these bone metastases [106]. These data indicate that TGF- $\beta$ signaling is prominent in bone metastases compared with other metastatic sites and that inhibiting either the TGF- $\beta$ pathway or osteoclastic bone resorption can impair this activity.

Further investigation of the specific functions of Smad2 and Smad 3 in TGF- $\beta$-induced responses in breast cancer cells in vitro and in vivo for breast cancer metastasis have recently been undertaken. Studies have shown that Smad2 and Smad3 differentially affect breast cancer bone metastasis formation in vivo [107]. Knockdown of Smad3 in breast cancer cells in vivo resulted in prolonged latency and delayed growth of bone metastasis. However, Smad2 knockdown resulted in a more aggressive phenotype 
compared with controls. Furthermore, the data suggest that bone-derived TGF- $\beta$, released as a consequence of osteoclastic bone resorption, is the major source of TGF- $\beta$ to act on tumour cells in bone. Overexpression of BMP-7 in breast cancer cells decreased the development of bone metastases in mice, but had no effect on orthotopic tumours $[25,108]$. BMP7 was found to antagonize TGF- $\beta /$ Smad signaling. Therefore, BMP-7 may be useful as an inhibitor of bone metastases [109-111].

Another unique aspect of the bone microenvironment is hypoxia. Bone is a hypoxic microenvironment and hypoxia has also been implicated to enhance tumour growth and metastasis [112]. TGF- $\beta$ and hypoxia signaling pathways in breast cancer cells were additive to induce vascular endothelial growth factor (VEGF) and CXCR4, via hypoxia-inducible factor- $1 \alpha$ (HIF-1 $\alpha)$ in vitro. HIF- $1 \alpha$ and TGF- $\beta$ pathways were inhibited in breast tumour cells using shRNA against HIF- $1 \alpha$ and dominant negative T $\beta R I I$ approaches $[99,113]$. In vivo, inhibition of either pathway decreased bone metastasis, but there was no additional effect on the development of bone metastasis with a double blockade. In contrast, treatment with pharmacologic inhibitors targeting both pathways decreased bone metastases more than either alone [99].

Preclinical studies have indicated that tumour cells express a number of genes which encode for proteins that act at different sites of the metastatic cascade as well as at the bone site. For example, several studies have shown that tumours cells produce adhesive molecules that promote binding to marrow stromal cells and bone matrix. These adhesive interactions increase tumour production of angiogenic and bone resorbing factors that enhance tumour growth in bone $[114,115]$.

\section{Breast to Lung Metastasis}

There is evidence that TGF- $\beta$ can primes breast cancer cells for metastasis to the lungs. This is based on the study by Padua et al. which showed that the process is dependent on the induction of angiopoietin-like 4 (ANGPTL4) by TGF- $\beta$ via the Smad signaling pathway [29]. TGF- $\beta$ induction of Angpt14 in cancer cells that are about to enter the circulation enhances their subsequent retention in the lungs, but not in the bone. Tumour cell-derived Angptl4 disrupts vascular endothelial cell-cell junctions, increases the permeability of lung capillaries, and facilitates the transendothelial passage of tumour cells [116]. It is suggested that the primary breast tumour microenvironment induces the expression of cytokines in departing tumour cells, enabling these cells to disrupt lung capillary walls and seed pulmonary metastases [29].

Functional studies have demonstrated that Id1 and its closely related family member Id 3 are required for tumour initiating functions, both in the context of primary tumour formation and during metastatic colonization of the lung microenvironment [117]. In vivo characterization of lung metastatic progression revealed that Id 1 and Id 3 facilitate sustained proliferation during the early stages of metastatic colonization, subsequent to extravasation into the lung parenchyma. Sadej et al. have shown that attenuation of TGF- $\beta 1$-induced responses correlated with reduced retention in the lung vascular bed, inhibition of pneumocyteinduced scattering of breast cancer cells in threedimensional Matrigel, and decrease in experimental metastasis to the lungs. These results identify CD151 as a positive regulator of TGF- $\beta 1$-initiated signaling and highlight the important role played by this tetraspanin in TGF$\beta 1$-induced breast cancer metastasis [118].

The role of TGF- $\beta$ coreceptor endoglin has also been studied in breast lung metastasis. Ectopic expression of endoglin in a breast cancer cell line blocked TGF- $\beta$ enhanced cell motility and invasion and reduced lung colonization in an in vivo metastasis model [119]. Endoglin does not modulate Smad-mediated TGF- $\beta$ signaling in breast cells but attenuates the cytoskeletal remodeling to impair cell migration and invasion [120].

\section{Perspectives}

In numerous models of breast cancer associated invasion and metastasis, activated TGF- $\beta$ signaling induces increased aggressiveness. Activated TGF- $\beta$ signaling has been observed in breast cancer bone metastases and there have also been many specific studies to analyse the role of TGF- $\beta$ in tumour metastasis. The role that TGF- $\beta$ plays in this complex, multi-step process is becoming clearer. New methods of research, such as the collagen-embedded spheroid system [59] and other three-dimensional coculture assays [121], offer a valuable method to study the crucial microenvironmental cues that may be lost in twodimensional culture assay with a plastic substrata.

In order to dissect the TGF- $\beta /$ Smad pathway, which underlies the complex biological responses in the mammary epithelium, a new method to generate conditionally immortalized mammary epithelial cells was developed. The method involves the intercrossing of the "Immortomouse", which expresses a temperature-sensitive mutant of the simian virus-40 large T-antigen, with mice of different Smad genotypes. Thus, conditionally immortalized mammary epithelial cell cultures can be derived from the mammary glands of offspring from these crosses [122]. Further dissection of the signaling pathways involved and elucidation on which signaling components are shared and distinct between tumour suppression and tumour promoting role of TGF- $\beta$, may lead to novel pharmacological targets 
for the intervention of breast cancer progression, while leaving the tumour suppressive effects of TGF- $\beta$ intact.

Stroma cells, together with ECM components, provide the microenvironment that is pivotal for cancer cell growth, invasion and metastatic progression. Crucial in this process are fibroblasts that are located in the vicinity of the neoplastic epithelial cells. They are able to modify the phenotype of the epithelial cells by direct cell-to-cell contacts, through soluble factors or by modification of extracellular matrix components. Seminal functional studies in various cancer types, including breast, colon, prostate and lung cancer, have confirmed the concept that fibroblasts can determine the fate of the epithelial cell, since they are able to promote malignant conversion as well as to revert tumour cells to a normal phenotype. The study by Kojima et al. suggests that the autocrine-signaling mechanism of TGF- $\beta$ in the tumour-stroma interactions may prove to be an attractive therapeutic target to bock the evolution of tumour-promoting CAFs [70].

Clear definitions of the molecular and cellular contexts that are permissive for the tumour suppressor versus oncogenic activities of TGF- $\beta$ are allowing new therapeutic opportunities to emerge. The most obvious therapeutic challenge in targeting the TGF- $\beta$ signaling pathway in breast cancer is: how to restore the lost tumour suppressor function while either eliminating or preventing acquired pro-oncogenic effects [123]. Unfortunately late-stage invasive, metastatic breast cancer is typically characterized by locally or systemically elevated TGF- $\beta$ levels. This elevation of TGF- $\beta$ is coupled with diminished responsiveness of tumour cells to its suppressor functions, as discussed throughout this review. TGF- $\beta$ antagonists could be efficacious. However, given the roles of TGF- $\beta$ on normal tissue homeostasis, the antagonist design and/or delivery mode will have to be optimized to minimize adverse effects.

In 2010, Ganapathy et al. investigated the possible clinical utility of TGF- $\beta$ antagonists in a human metastatic basal-like breast cancer model [124]. Two TGF- $\beta$ pathway antagonists, 1D11 (a mouse monoclonal pan-TGF- $\beta$ neutralizing antibody) and LY2109761 (a chemical inhibitor of T $\beta$ RI and T $\beta$ RII kinases) were tested on MDA-MB-231. $1 \mathrm{D} 11$ and LY2109761 were shown to effectively block TGF- $\beta$-induced phosphorylation of receptor-associated Smads in vitro. Moreover, both antagonists inhibited TGF- $\beta$ stimulated in vitro migration and invasiveness. In addition, both antagonists significantly reduced the metastatic burden to either lungs or bones in vivo. These studies not only support the notion that TGF- $\beta$ plays an important role in both bone-and lung metastases of basal-like breast cancer, but also that targeting of the TGF- $\beta$ pathway holds promise as a novel therapeutic approach for metastatic basal-like breast cancer.
TGF- $\beta$-specific inhibitors based on blockade of synthesis, ligand/receptor binding or receptor kinase signaling are in clinical trials [125]. Clearly, further research can refine the therapeutic rationale by focusing on drug scheduling and delivery, identifying patients who will benefit most from such therapy, and combining therapeutic modalities such that cancer is eliminated without normal tissue toxicity or long term health effects.

\section{Concluding Remarks}

The role of TGF- $\beta$ signaling in breast cancer cell invasion and metastasis involves multiple factors. Expression of TGF- $\beta$ promotes a more aggressive tumour phenotype. TGF- $\beta$ is known to be involved in the process of EMT, invasion and metastasis, and can influence the microenvironment. Crosstalk between the breast tumour cells and the microenvironment can promote a bone or lung metastasis. TGF- $\beta$ is involved in the crosstalk by recruiting and regulating the activity of multiple cell types. Whereas much is understood about the effects of these factors in cancer cells at the primary tumour site, continued research is necessary to clearly understand metastatic breast cancer. Understanding how TGF- $\beta$ allows the tumours to progressive to the metastatic phenotype may help to identify potential targets for therapeutic intervention to halt tumour growth and bone metastasis.

Acknowledgements Special thanks are for our colleagues for valuable discussions and Hans van Dam for critical reading of the manuscript.

Open Access This article is distributed under the terms of the Creative Commons Attribution Noncommercial License which permits any noncommercial use, distribution, and reproduction in any medium, provided the original author(s) and source are credited.

\section{References}

1. Porter PL. Global trends in breast cancer incidence and mortality. Salud Pública Méx. 2009;51 Suppl 2:s141-6.

2. Sanchez-Zamorano LM, Flores-Luna L, Angeles-Llerenas A, et al. Healthy lifestyle on the risk of breast cancer. Cancer epidemiology, biomarkers \& prevention: a publication of the American Association for Cancer Research, cosponsored by the American Society of Preventive Oncology 2011.

3. Travis RC, Reeves GK, Green J, et al. Gene-environment interactions in 7610 women with breast cancer: prospective evidence from the Million Women Study. Lancet. 2010;375(9732):2143-51.

4. Buck MB, Knabbe C. TGF- $\beta$ signaling in breast cancer. Ann NY Acad Sci. 2006;1089:119-26.

5. ten Dijke P, Hill CS. New insights into TGF- $\beta$-Smad signalling. Trends Biochem Sci. 2004;29(5):265-73.

6. Moustakas A, Heldin CH. Non-Smad TGF- $\beta$ signals. J Cell Sci. 2005;118(Pt 16):3573-84. 
7. Zhang YE. Non-Smad pathways in TGF- $\beta$ signaling. Cell Res. 2009;19(1):128-39.

8. Lee MK, Pardoux C, Hall MC, et al. TGF- $\beta$ activates Erk MAP kinase signalling through direct phosphorylation of ShcA. EMBO J. 2007;26(17):3957-67.

9. Bhowmick NA, Zent R, Ghiassi $M$, et al. Integrin $\beta 1$ signaling is necessary for transforming growth factor- $\beta$ activation of $\mathrm{p} 38 \mathrm{MAPK}$ and epithelial plasticity. J Biol Chem. 2001;276(50):46707-13.

10. Edlund S, Landstrom $\mathrm{M}$, Heldin $\mathrm{CH}$, et al. Transforming growth factor- $\beta$-induced mobilization of actin cytoskeleton requires signaling by small GTPases Cdc42 and RhoA. Mol Biol Cell. 2002;13(3):902-14.

11. Wilkes MC, Murphy SJ, Garamszegi N, et al. Cell-type-specific activation of PAK2 by transforming growth factor $\beta$ independent of Smad2 and Smad3. Mol Cell Biol. 2003;23(23):8878-89.

12. Barcellos-Hoff MH, Akhurst RJ. Transforming growth factor- $\beta$ in breast cancer: too much, too late. Breast Cancer Res. 2009;11(1):202.

13. Kleuser B, Malek D, Gust R, et al. 17- $\beta$-estradiol inhibits transforming growth factor- $\beta$ signaling and function in breast cancer cells via activation of extracellular signal-regulated kinase through the G protein-coupled receptor 30. Mol Pharmacol. 2008;74(6):1533-43.

14. Hinshelwood RA, Huschtscha LI, Melki J, et al. Concordant epigenetic silencing of transforming growth factor- $\beta$ signaling pathway genes occurs early in breast carcinogenesis. Cancer Res. 2007;67(24):11517-27.

15. Akhurst RJ, Derynck R. TGF- $\beta$ signaling in cancer-a doubleedged sword. Trends Cell Biol. 2001;11(11):S44-51.

16. Turashvili G, Bouchal J, Baumforth K, et al. Novel markers for differentiation of lobular and ductal invasive breast carcinomas by laser microdissection and microarray analysis. BMC Cancer. 2007;7:55.

17. Figueroa JD, Flanders KC, Garcia-Closas M, et al. Expression of TGF- $\beta$ signaling factors in invasive breast cancers: relationships with age at diagnosis and tumor characteristics. Breast Cancer Res Treat. 2010;121(3):727-35.

18. Zhang S, Royer R, Li S, et al. Frequencies of BRCA1 and BRCA2 mutations among 1,342 unselected patients with invasive ovarian cancer. Gynecol Oncol. 2011.

19. Li J, Zhu H, Chen T, et al. TGF- $\beta 1$ and BRCA2 expression are associated with clinical factors in breast cancer. Cell Biochem Biophys. 2011.

20. Xu J, Lamouille S, Derynck R. TGF- $\beta$-induced epithelial to mesenchymal transition. Cell Res. 2009;19(2):156-72.

21. Miyazono K. Transforming growth factor- $\beta$ signaling in epithelial-mesenchymal transition and progression of cancer. Proc Jpn Acad B Phys Biol Sci. 2009;85(8):314-23.

22. Massagué J. TGF $\beta$ in cancer. Cell. 2008;134(2):215-30.

23. ten Dijke P, Goumans MJ, Pardali E. Endoglin in angiogenesis and vascular diseases. Angiogenesis. 2008;11(1):79-89.

24. Flavell RA, Sanjabi S, Wrzesinski SH, et al. The polarization of immune cells in the tumour environment by TGF- $\beta$. Nature reviews. Immunology. 2010;10(8):554-67.

25. Buijs JT, Henriquez NV, van Overveld PG, et al. Bone morphogenetic protein 7 in the development and treatment of bone metastases from breast cancer. Cancer Res. 2007;67(18):8742-51.

26. Bos PD, Nguyen DX, Massagué J. Modeling metastasis in the mouse. Curr Opin Pharmacol. 2010;10(5):571-7.

27. Tsuji T, Ibaragi S, Hu GF. Epithelial-mesenchymal transition and cell cooperativity in metastasis. Cancer Res. 2009;69(18):7135-9.

28. Grunert S, Jechlinger M, Beug H. Diverse cellular and molecular mechanisms contribute to epithelial plasticity and metastasis. Nature reviews. Molec Cell Biol. 2003;4(8):657-65.

29. Padua D, Zhang XH, Wang Q, et al. TGF- $\beta$ primes breast tumors for lung metastasis seeding through angiopoietin-like 4. Cell. 2008;133(1):66-77.
30. Godde NJ, Galea RC, Elsum IA, et al. Cell polarity in motion: redefining mammary tissue organization through EMT and cell polarity transitions. J Mammary Gland Biol Neoplasia. 2010;15 (2):149-68

31. Zavadil J, Bottinger EP. TGF- $\beta$ and epithelial-to-mesenchymal transitions. Oncogene. 2005;24(37):5764-74.

32. Miettinen PJ, Ebner R, Lopez AR, et al. TGF- $\beta$ induced transdifferentiation of mammary epithelial cells to mesenchymal cells: involvement of type I receptors. J Cell Biol. 1994;127(6 Pt 2):2021-36.

33. Piek E, Moustakas A, Kurisaki A, et al. TGF-( $\beta$ ) type I receptor/ ALK-5 and Smad proteins mediate epithelial to mesenchymal transdifferentiation in NMuMG breast epithelial cells. J Cell Sci. 1999;112(Pt 24):4557-68.

34. Lindley LE, Briegel KJ. Molecular characterization of TGF $\beta$ induced epithelial-mesenchymal transition in normal finite lifespan human mammary epithelial cells. Biochem Biophys Res Commun. 2010;399(4):659-64.

35. Jo M, Lester RD, Montel V, et al. Reversibility of epithelialmesenchymal transition (EMT) induced in breast cancer cells by activation of urokinase receptor-dependent cell signaling. J Biol Chem. 2009;284(34):22825-33.

36. Trimboli AJ, Fukino K, de Bruin A, et al. Direct evidence for epithelial-mesenchymal transitions in breast cancer. Cancer Res. 2008;68(3):937-45.

37. Turashvili G, Bouchal J, Ehrmann J, et al. Novel immunohistochemical markers for the differentiation of lobular and ductal invasive breast carcinomas. Biomedical papers of the Medical Faculty of the University Palacky, Olomouc, Czechoslovakia. 2007;151(1):59-64.

38. Micalizzi DS, Farabaugh SM, Ford HL. Epithelial-mesenchymal transition in cancer: parallels between normal development and tumor progression. J Mammary Gland Biol Neoplasia. 2010;15(2):117-34.

39. Christofori G. New signals from the invasive front. Nature. 2006;441(7092):444-50

40. Vincent T, Neve EP, Johnson JR, et al. A SNAIL1-SMAD3/4 transcriptional repressor complex promotes TGF- $\beta$ mediated epithelial-mesenchymal transition. Nat Cell Biol. 2009;11(8):943-50.

41. Thuault S, Valcourt U, Petersen M, et al. Transforming growth factor- $\beta$ employs HMGA2 to elicit epithelial-mesenchymal transition. J Cell Biol. 2006;174(2):175-83.

42. Viloria-Petit AM, David L, Jia JY, et al. A role for the TGF $\beta$ Par6 polarity pathway in breast cancer progression. Proc Natl Acad Sci USA. 2009;106(33):14028-33.

43. Shirakihara T, Horiguchi K, Miyazawa K, et al. TGF- $\beta$ regulates isoform switching of FGF receptors and epithelial-mesenchymal transition. EMBO J. 2011;30(4):783-95.

44. Wendt MK, Smith JA, Schiemann WP. Transforming growth factor- $\beta$-induced epithelial-mesenchymal transition facilitates epidermal growth factor-dependent breast cancer progression. Oncogene. 2010;29(49):6485-98.

45. Micalizzi DS, Christensen KL, Jedlicka P, et al. The Six 1 homeoprotein induces human mammary carcinoma cells to undergo epithelial-mesenchymal transition and metastasis in mice through increasing TGF- $\beta$ signaling. J Clin Invest. 2009;119(9):2678-90.

46. Micalizzi DS, Wang CA, Farabaugh SM, et al. Homeoprotein Six 1 increases TGF- $\beta$ Type I receptor and converts TGF- $\beta$ signaling from suppressive to supportive for tumor growth. Cancer Res. 2010;70(24):10371-80.

47. Deckers M, van Dinther M, Buijs J, et al. The tumor suppressor Smad4 is required for transforming growth factor $\beta$-induced epithelial to mesenchymal transition and bone metastasis of breast cancer cells. Cancer Res. 2006;66(4):2202-9.

48. Thuault S, Tan EJ, Peinado H, et al. HMGA2 and Smads coregulate SNAIL1 expression during induction of epithelial-tomesenchymal transition. J Biol Chem. 2008;283(48):33437-46. 
49. Gregory PA, Bert AG, Paterson EL, et al. The miR-200 family and miR-205 regulate epithelial to mesenchymal transition by targeting ZEB1 and SIP1. Nat Cell Biol. 2008;10(5):593-601.

50. Bakin AV, Tomlinson AK, Bhowmick NA, et al. Phosphatidylinositol 3-kinase function is required for transforming growth factor $\beta$-mediated epithelial to mesenchymal transition and cell migration. J Biol Chem. 2000;275(47):36803-10.

51. de Graauw M, van Miltenburg MH, Schmidt MK, et al. Annexin A1 regulates TGF- $\beta$ signaling and promotes metastasis formation of basal-like breast cancer cells. Proc Natl Acad Sci USA. 2010;107(14):6340-5.

52. Araki S, Eitel JA, Batuello $\mathrm{CN}$, et al. TGF- $\beta 1$-induced expression of human $\mathrm{Mdm} 2$ correlates with late-stage metastatic breast cancer. J Clin Investig. 2010;120(1):290-302.

53. Sabbah M, Prunier C, Ferrand N, et al. CCN5, a novel transcriptional repressor of transforming growth factor- $\beta$ signaling pathway. Mol Cell Biol. 2011.

54. Mareel M, Oliveira MJ, Madani I. Cancer invasion and metastasis: interacting ecosystems. Virchows Archiv: An International Journal of Pathology. 2009;454(6):599-622.

55. Mareel M, Leroy A. Clinical, cellular, and molecular aspects of cancer invasion. Physiol Rev. 2003;83(2):337-76.

56. Hu M, Yao J, Carroll DK, et al. Regulation of in situ to invasive breast carcinoma transition. Cancer Cell. 2008;13(5):394-406.

57. Luo YP, Zhou H, Krueger J, et al. The role of proto-oncogene Fra-1 in remodeling the tumor microenvironment in support of breast tumor cell invasion and progression. Oncogene. 2010;29 (5):662-73.

58. Mandal S, Johnson KR, Wheelock MJ. TGF- $\beta$ induces formation of F-actin cores and matrix degradation in human breast cancer cells via distinct signaling pathways. Exp Cell Res. 2008;314(19):3478-93.

59. Wiercinska E, Naber HP, Pardali E, et al. The TGF- $\beta /$ Smad pathway induces breast cancer cell invasion through the upregulation of matrix metalloproteinase 2 and 9 in a spheroid invasion model system. Breast Cancer Res Treat. 2010.

60. Giampieri S, Manning C, Hooper S, et al. Localized and reversible TGF- $\beta$ signalling switches breast cancer cells from cohesive to single cell motility. Nat Cell Biol. 2009;11 (11):1287-96.

61. McAllister SS, Weinberg RA. Tumor-host interactions: a farreaching relationship. J Clin Oncol: Official Journal of the American Society of Clinical Oncology. 2010;28(26):4022-8.

62. Park CC, Bissell MJ, Barcellos-Hoff MH. The influence of the microenvironment on the malignant phenotype. Mol Med Today. 2000;6(8):324-9.

63. Mueller MM, Fusenig NE. Friends or foes - bipolar effects of the tumour stroma in cancer. Nat Rev Cancer. 2004;4(11):839-49.

64. Sieweke MH, Bissell MJ. The tumor-promoting effect of wounding: a possible role for TGF- $\beta$-induced stromal alterations. Crit Rev Oncog. 1994;5(2-3):297-311.

65. Shekhar MP, Pauley R, Heppner G. Host microenvironment in breast cancer development: extracellular matrix-stromal cell contribution to neoplastic phenotype of epithelial cells in the breast. Breast Cancer Res. 2003;5(3):130-5.

66. Olsen CJ, Moreira J, Lukanidin EM, et al. Human mammary fibroblasts stimulate invasion of breast cancer cells in a threedimensional culture and increase stroma development in mouse xenografts. BMC Cancer. 2010;10:444.

67. Stuelten CH, Busch JI, Tang B, et al. Transient tumor-fibroblast interactions increase tumor cell malignancy by a TGF- $\beta$ mediated mechanism in a mouse xenograft model of breast cancer. PLoS ONE. 2010;5(3):e9832.

68. Karnoub AE, Dash AB, Vo AP, et al. Mesenchymal stem cells within tumour stroma promote breast cancer metastasis. Nature. 2007;449(7162):557-63.
69. Haviv I, Polyak K, Qiu W, et al. Origin of carcinoma associated fibroblasts. Cell Cycle. 2009;8(4):589-95.

70. Kojima Y, Acar A, Eaton EN, et al. Autocrine TGF- $\beta$ and stromal cell-derived factor-1 (SDF-1) signaling drives the evolution of tumor-promoting mammary stromal myofibroblasts. Proc Natl Acad Sci USA. 2010;107(46):20009-14.

71. Bhowmick NA, Chytil A, Plieth D, et al. TGF- $\beta$ signaling in fibroblasts modulates the oncogenic potential of adjacent epithelia. Science. 2004;303(5659):848-51.

72. Cheng N, Bhowmick NA, Chytil A, et al. Loss of TGF- $\beta$ type II receptor in fibroblasts promotes mammary carcinoma growth and invasion through upregulation of TGF- $\alpha-$, MSP- and HGFmediated signaling networks. Oncogene. 2005;24(32):5053-68.

73. Cheng N, Chytil A, Shyr Y, et al. Transforming growth factor- $\beta$ signaling-deficient fibroblasts enhance hepatocyte growth factor signaling in mammary carcinoma cells to promote scattering and invasion. Molec Cancer Res. 2008;6(10):1521-33.

74. Barcellos-Hoff MH, Ravani SA. Irradiated mammary gland stroma promotes the expression of tumorigenic potential by unirradiated epithelial cells. Cancer Res. 2000;60(5):1254-60.

75. Barcellos-Hoff MH. Radiation-induced transforming growth factor $\beta$ and subsequent extracellular matrix reorganization in murine mammary gland. Cancer Res. 1993;53(17):3880-6.

76. Casey TM, Eneman J, Crocker A, et al. Cancer associated fibroblasts stimulated by transforming growth factor $\beta 1$ (TGF$\beta 1$ ) increase invasion rate of tumor cells: a population study. Breast Cancer Res Treat. 2008;110(1):39-49.

77. Mantovani A, Marchesi F, Porta C, et al. Inflammation and cancer: breast cancer as a prototype. Breast. 2007;16 Suppl 2:S27-33.

78. Bierie B, Moses HL. TGF- $\beta$ and cancer. Cytokine Growth Factor Rev. 2006;17(1-2):29-40.

79. Marigo I, Dolcetti L, Serafini P, et al. Tumor-induced tolerance and immune suppression by myeloid derived suppressor cells. Immunol Rev. 2008;222:162-79.

80. Gallina G, Dolcetti L, Serafini P, et al. Tumors induce a subset of inflammatory monocytes with immunosuppressive activity on CD8+ T cells. J Clin Investig. 2006;116(10):2777-90.

81. Yang L, Huang J, Ren X, et al. Abrogation of TGF- $\beta$ signaling in mammary carcinomas recruits Gr- $1+\mathrm{CD} 11 \mathrm{~b}+$ myeloid cells that promote metastasis. Cancer Cell. 2008;13(1):23-35.

82. Oliveira MJ, Van Damme J, Lauwaet T, et al. $\beta$-casein-derived peptides, produced by bacteria, stimulate cancer cell invasion and motility. EMBO J. 2003;22(22):6161-73.

83. Leask A, Abraham DJ. TGF- $\beta$ signaling and the fibrotic response. FASEB J: Official Publication of the Federation of American Societies for Experimental Biology. 2004;18(7):816-27.

84. Kang Y, He W, Tulley S, et al. Breast cancer bone metastasis mediated by the Smad tumor suppressor pathway. Proc Natl Acad Sci USA. 2005;102(39):13909-14.

85. Alarmo EL, Parssinen J, Ketolainen JM, et al. BMP7 influences proliferation, migration, and invasion of breast cancer cells. Cancer Lett. 2009;275(1):35-43.

86. Ketolainen JM, Alarmo EL, Tuominen VJ, et al. Parallel inhibition of cell growth and induction of cell migration and invasion in breast cancer cells by bone morphogenetic protein 4 . Breast Cancer Res Treat. 2010;124(2):377-86.

87. Alarmo EL, Korhonen T, Kuukasjarvi T, et al. Bone morphogenetic protein 7 expression associates with bone metastasis in breast carcinomas. Ann Oncol: Official Journal of the European Society for Medical Oncology/ESMO. 2008;19(2):308-14.

88. Blair HC, Athanasou NA. Recent advances in osteoclast biology and pathological bone resorption. Histol Histopathol. 2004;19 (1):189-99.

89. Henderson MA, Danks JA, Slavin JL, et al. Parathyroid hormone-related protein localization in breast cancers predict improved prognosis. Cancer Res. 2006;66(4):2250-6. 
90. Powell GJ, Southby J, Danks JA, et al. Localization of parathyroid hormone-related protein in breast cancer metastases: increased incidence in bone compared with other sites. Cancer Res. 1991;51(11):3059-61.

91. Guise TA, Yin JJ, Taylor SD, et al. Evidence for a causal role of parathyroid hormone-related protein in the pathogenesis of human breast cancer-mediated osteolysis. J Clin Investig. 1996;98(7):1544-9.

92. Yin JJ, Selander K, Chirgwin JM, et al. TGF- $\beta$ signaling blockade inhibits PTHrP secretion by breast cancer cells and bone metastases development. J Clin Invest. 1999;103(2):197-206.

93. Kakonen SM, Selander KS, Chirgwin JM, et al. Transforming growth factor- $\beta$ stimulates parathyroid hormone-related protein and osteolytic metastases via Smad and mitogen-activated protein kinase signaling pathways. J Biol Chem. 2002;277 (27):24571-8.

94. Evtimova V, Schwirzke M, Tarbe N, et al. Identification of breast cancer metastasis-associated genes by chip technology. Anticancer Res. 2001;21(6A):3799-806.

95. Watson MA, Ylagan LR, Trinkaus KM, et al. Isolation and molecular profiling of bone marrow micrometastases identifies TWIST1 as a marker of early tumor relapse in breast cancer patients. Clin Cancer Res: An Official Journal of the American Association for Cancer Research. 2007;13(17):5001-9.

96. Juarez P, Guise TA. TGF- $\beta$ in cancer and bone: implications for treatment of bone metastases. Bone 2010.

97. Lu X, Wang Q, Hu G, et al. ADAMTS1 and MMP1 proteolytically engage EGF-like ligands in an osteolytic signaling cascade for bone metastasis. Genes Dev. 2009;23(16):1882-94.

98. Kang Y, Massagué J. Epithelial-mesenchymal transitions: twist in development and metastasis. Cell. 2004;118(3):277-9.

99. Dunn LK, Mohammad KS, Fournier PG, et al. Hypoxia and TGF- $\beta$ drive breast cancer bone metastases through parallel signaling pathways in tumor cells and the bone microenvironment. PLoS ONE. 2009;4(9):e6896.

100. Katoh M. Integrative genomic analyses of CXCR4: transcriptional regulation of CXCR4 based on TGF $\beta$, Nodal, Activin signaling and POU5F1, FOXA2, FOXC2, FOXH1, SOX17, and GFI1 transcription factors. Int J Oncol. 2010;36(2):415-20.

101. Shimo T, Kubota S, Yoshioka N, et al. Pathogenic role of connective tissue growth factor $(\mathrm{CTGF} / \mathrm{CCN} 2)$ in osteolytic metastasis of breast cancer. J Bone Miner Res: The Official Journal of the American Society for Bone and Mineral Research. 2006;21(7):1045-59.

102. Alarmo EL, Kallioniemi A. Bone morphogenetic proteins in breast cancer: dual role in tumourigenesis? Endocr-Relat Cancer. 2010;17(2):R123-39.

103. Johnson RW, Nguyen MP, Padalecki SS, et al. TGF- $\beta$ promotion of Gli2-induced expression of parathyroid hormone-related protein, an important osteolytic factor in bone metastasis, is independent of canonical hedgehog signaling. Cancer Res. 2011;71(3):822-31.

104. Futakuchi M, Nannuru KC, Varney ML, et al. Transforming growth factor- $\beta$ signaling at the tumor-bone interface promotes mammary tumor growth and osteoclast activation. Cancer Sci. 2009;100(1):71-81.

105. Bierie B, Stover DG, Abel TW, et al. Transforming growth factor- $\beta$ regulates mammary carcinoma cell survival and interaction with the adjacent microenvironment. Cancer Res. 2008;68(6):1809-19.

106. Korpal M, Yan J, Lu X, et al. Imaging transforming growth factor- $\beta$ signaling dynamics and therapeutic response in breast cancer bone metastasis. Nat Med. 2009;15(8):960-6.

107. Petersen M, Pardali E, van der Horst G, et al. Smad2 and Smad3 have opposing roles in breast cancer bone metastasis by differentially affecting tumor angiogenesis. Oncogene. 2010;29 (9):1351-61.

108. Buijs JT, Que I, Lowik CW, et al. Inhibition of bone resorption and growth of breast cancer in the bone microenvironment. Bone. 2009;44(2):380-6.

109. Buijs JT, Henriquez NV, van Overveld PG, et al. TGF- $\beta$ and BMP7 interactions in tumour progression and bone metastasis. Clin Exp Metastasis. 2007;24(8):609-17.

110. Buijs JT, Kuijpers CC, van der Pluijm G. Targeted therapy options for treatment of bone metastases; beyond bisphosphonates. Curr Pharm Des. 2010;16(27):3015-27.

111. Buijs JT, Petersen M, van der Horst G, et al. Bone morphogenetic proteins and its receptors; therapeutic targets in cancer progression and bone metastasis? Curr Pharm Des. 2010;16 (11):1291-300.

112. Kingsley LA, Fournier PG, Chirgwin JM, et al. Molecular biology of bone metastasis. Mol Cancer Ther. 2007;6 (10):2609-17.

113. McMahon S, Charbonneau M, Grandmont S, et al. Transforming growth factor $\beta 1$ induces hypoxia-inducible factor- 1 stabilization through selective inhibition of PHD2 expression. J Biol Chem. 2006;281(34):24171-81.

114. van der Pluijm G, Sijmons B, Vloedgraven H, et al. Monitoring metastatic behavior of human tumor cells in mice with speciesspecific polymerase chain reaction: elevated expression of angiogenesis and bone resorption stimulators by breast cancer in bone metastases. J Bone Miner Res: The Official Journal of the American Society for Bone and Mineral Research. 2001;16 (6):1077-91.

115. Davies S, Jiang WG. ALCAM, activated leukocyte cell adhesion molecule, influences the aggressive nature of breast cancer cells, a potential connection to bone metastasis. Anticancer Res. 2010;30(4):1163-8

116. Galaup A, Cazes A, Le Jan S, et al. Angiopoietin-like 4 prevents metastasis through inhibition of vascular permeability and tumor cell motility and invasiveness. Proc Natl Acad Sci USA. 2006;103(49):18721-6.

117. Gupta GP, Perk J, Acharyya S, et al. ID genes mediate tumor reinitiation during breast cancer lung metastasis. Proc Natl Acad Sci USA. 2007;104(49):19506-11.

118. Sadej R, Romanska H, Kavanagh D, et al. Tetraspanin CD151 regulates transforming growth factor $\beta$ signaling: implication in tumor metastasis. Cancer Res. 2010;70(14):6059-70.

119. Henry LA, Johnson DA, Sarrio D, et al. Endoglin expression in breast tumor cells suppresses invasion and metastasis and correlates with improved clinical outcome. Oncogene. 2010.

120. Perez-Gomez E, Del Castillo G, Juan Francisco S, et al. The role of the TGF- $\beta$ coreceptor endoglin in cancer. Scientific World Journal. 2010;10:2367-84.

121. Lee GY, Kenny PA, Lee EH, et al. Three-dimensional culture models of normal and malignant breast epithelial cells. Nat Meth. 2007;4(4):359-65.

122. Kohn EA, Du Z, Sato M, et al. A novel approach for the generation of genetically modified mammary epithelial cell cultures yields new insights into TGF- $\beta$ signaling in the mammary gland. Breast Cancer Res. 2010;12(5):R83.

123. Wakefield LM, Roberts AB. TGF- $\beta$ signaling: positive and negative effects on tumorigenesis. Curr Opin Genet Dev. 2002;12(1):22-9.

124. Ganapathy V, Ge R, Grazioli A, et al. Targeting the transforming growth factor- $\beta$ pathway inhibits human basal-like breast cancer metastasis. Mol Cancer. 2010;9:122.

125. Saunier EF, Akhurst RJ. TGF- $\beta$ inhibition for cancer therapy. Curr Cancer Drug Targets. 2006;6(7):565-78. 